JANUSZ MACIASZEK

University of Łódź

Department of Philosophy

januszm@uni.lodz.pl

\title{
THE NOTION OF ACTION IN KOTARBIŃSKI'S PRAXEOLOGY
}

\begin{abstract}
The aim of the paper is to recast main notions of Tadeusz Kotarbiński's praxeolology in terms of Donald Davidson's theory of action. The paper focuses also on ontological commitments of both theories. Though Kotarbiński did not admit events in his reistic ontology, in his praxeology conceived actions as compounded entities without any clue how to reduce the parts of action into things. I argue that Kotarbiński's restrictive ontological reism cannot be maintained in case of praxeology, and propose to admit events as existing objects. This enables to simplify extremely complicated net of Kotarbiński's concepts and to find the counterparts of the parts of action in Kotarbiński's sense in Davidson's theory of action.
\end{abstract}

Keywords. Act, action, agency, agent, cause, effect, praxeology, reism.

\section{Introductory remarks}

Kotarbiński's praxeology, i.e. the theory of efficient action, is based on his philosophy of action, which comprises a rather complicated net of notions including the very notion of action, event, causal relation, agent, agency, and many more. This conceptual apparatus was originally presented in some early praxeological works (see KOTARBIŃSKI [1999]), in Treatise on Good Work [1955], and later, in an abbreviated form, in $A B C$ of Practicality (see: KOTARBIŃSKI [1972]. Kotarbiński's reason to focus attention on philosophy of action was to give a useful theoretical tools for praxeology which was conceived as a philosophical theory with straightforward practical applications. From this point of view, the applied action-theory notions should be, and in fact are, rather intuitive, though as in every theory, the meanings of natural-language terms have been explicated, and some new, rather artificial terms have been introduced.

On the other hand, Kotarbiński's theory of action was conceived by him as compatible with his philosophical position called reism or pansomatism. From 
a reistic viewpoint, events, actions, as well as properties and relations (e.g. causality) do not exist, and their names are onomatoids or ostensible names:

We deny the existence of something like the movement of a hand of a watch, the explosion of Vesuvius, the death of Caesar (...) (KOTARBIŃSKI [1961], (1929), p. 62).

The two demands, i.e. the use of intuitive praxeological terms and the denial of the existence of their referents, were reconciled by Kotarbiński's contention that ostensible names are eliminable from all contexts, i.e. all sentences with ostensible names can be translated onto equivalent reistically acceptable sentences with real names of individual objects called 'bodies', though, as we can learn from some examples given by Kotarbiński, the translation can be sometimes very troublesome, unintuitive, and even odd. ${ }^{1}$ In consequence, every ostensible notion appearing in his praxeology and philosophy of action is supposed to be, in principle, eliminable. As the collection of praxeological ostensible names forms a rather complicated system of interrelated notions, the practical reduction of unacceptable event-language to reistic language was a very difficult task and was carried out only in the case of some examples. In fact, Kotarbiński seemed to be fully satisfied with the very possibility of this translation and used the praxeological language full of forbidden terms without hesitation.

The main aim of this paper is to challenge Kotarbiński contention that names of events and actions can be eliminated from language and, in consequence, to acknowledge events and actions as existing individual objects. This enrichment of the original reistic ontology permits Kotarbiński's philosophy of action to be presented in a more coherent way. In order to achieve this goal, I reconstruct the main concepts of Kotarbiński's theory in terms of Donald Davidson's philosophy of action (see DAVIDSON [1980]). The choice of this perspective is not random, as Davidson's nominalistic philosophy in general, and his philosophy of action in particular, bears salient resemblance to Kotarbiński's theory. The application of Davidson's theoretical apparatus permits us to explicate better Kotarbiński's notion of free impulse (impuls dowolny), goal, and work (dzieło). It also enables us to establish the obvious and intuitive connection between an agent (sprawca) and his action. The proposed perspective can also help to solve some minor inconsistencies in Kotarbiński's theory.

\footnotetext{
${ }^{1}$ This can be considered as an example of a linguistic version of Ockham's razor - if a notion is eliminable from the language of the theory there is no reason to maintain the existence of its referent.
} 


\section{Action}

According to Kotarbiński, the main aim of praxeology is:

(...) the analytic description of the elements of action and its various forms. By the elements of action, we understand acting subjects, material (tworzywo), means, methods, goals, products (wytwory), etc. (Treatise: p. 17). ${ }^{2}$

With minor changes, the list is repeated in $A B C$ of Practicality:

In every action (..), act (..) take part various elements (..): agent (sprawca), material, product, free impulse (impuls dowolny), circumstances, effect, and goal (ABC, p. 32).

The every-day notion of action is rather vague and the notion of act is not only vague but ambiguous as well. One of the main aims of the philosophy of action is to clarify these notions. Kotarbiński consciously does not distinguish between every-day concepts of action and act, and introduces the neologism free impulse as one of the elements of action. From a reistic viewpoint the terms 'action' and 'act', as well as the names of some of their elements, are ostensible names without existing referents, which in principle can be eliminated from all contexts of use. But if the reduction of the notions is impossible, or at least implausible, then there is a good reason to enrich the ontology ${ }^{3}$. In the paper I try to apply the minimum of the strategy of enriching the ontology, just to avoid major conceptual difficulties of praxeological apparatus.

The first problem of Kotarbiński's notion of action we encounter in Treatise is the terminological one. In order to avoid it I depart from Kotarbiński's original terminology, and keeping the original notion of act unchanged, I will approximately identify action with free impulse, though I will not regard these terms as synonyms ${ }^{4}$. The proposed terminological change must cope with obvious connection between action (now conceived as free impulse) and other mentioned notions.

From Davidson's point of view, which I promote here, an action can be considered a goal-oriented event which is performed by an agent, and has effects compatible or not compatible with goals, or even unknown to the agent. I believe that this position is generally compatible with Kotarbiński's one. An action is always performed in certain circumstances and, in Kotarbiński's terms, its effects consist in changes in material that result in product. ${ }^{5}$ The intuitive

\footnotetext{
${ }^{2}$ All citations are in my translation.

${ }^{3}$ Kotarbiński's semantic motivations for reism were described in WOLEŃSKI [1985], pp. 208226.

${ }^{4}$ I will explain his point later. In general After Davidson I consider free impulse as a special form of description of action.

${ }^{5}$ Davidson does not apply this terminology.
} 
connection between action and other notions just indicated was comprised by Kotarbiński in his definition of action as rather informal inclusion: action embraces agent, effect, goal, etc. As the existence of compound entities of this sort is not unacceptable be reism, Kotarbiński's notion of action is obviously an ostensible name. But if the reistic reduction were possible, the mentioned connection should be explicated in a different way - it should be revealed on the linguistic level in translations of sentences about actions, effects, agents, etc. into reistic language. I do not believe that it is possible to fulfill this postulate, nevertheless, I believe that it can be accomplished in the weakened version of reduction proposed in this paper. The relation between an action conceived as an event, i.e. an existing entity, and other concepts consists in their application in description of the action.

In Action, Reasons, and Causes [1963], Davidson defines an action as an event caused by its reason conceived as a mental event. As we remember, Kotarbiński did not treat events as existing beings, and he proposed a reistic translation of sentences about events to sentences about changing objects, and not changes in objects. $^{6}$ In consequence, he proposed the reistic translation of sentences about the causal relation that holds between individual events to the sentences about changes in things. Let us consider Kotarbiński's original example: 'The explosion of Vesuvius destroyed Pompeii and Herculaneum' can be reduced to the reistic sentence 'Vesuvius exploded in such a way that it destroyed Pompeii and Herculaneum', where the name of the event 'the explosion of Vesuvius' has been eliminated (KOTARBIŃSKI [1986] (1929), p. 63 and WOLEŃSKI [1985], p. 211]. Unfortunately, the action-verb 'to destroy' is also an ostensible name that should be somehow eliminated. In consequence, the logical form of the proposed translation is rather unclear. The easiest solution is to translate 'to destroy' onto 'to cause the destruction of Pompeii and Herculaneum'. As destruction of an object is obviously an event, the phrase can be replaced by 'to cause Pompeii and Herculaneum to disintegrate', which would probably be acceptable by a reist if we managed to deal with the ostensible relational name 'to cause'. Kotarbiński's general idea was that relational names are in fact eliminable, and even if we use them, it does not commit us to accepting the existence of relations as their referents, e.g. Kotarbiński argued that there is no relation of being taller, but John and Peter can be related in such way that John is taller than Peter. Before examining the possibility of the reduction of sentences about events to sentences about changing objects, I will focus on Kotarbiński's approach to causality. ${ }^{7}$

\footnotetext{
${ }^{6}$ Changes are events which were rejected by Kotarbiński.

${ }^{7}$ Kotarbiński's views about causality constitute a rather complicated problem that I do not intend to solve here. In KOTARBIŃSKI [1929] he discusses the problem but is rather skeptical about the possibility of a definite solution see KOTARBIŃSKI [1961] (1929), pp. 269-274. Kotarbiński
} 
Causality, even if conceived as a relation holding between changing objects, is a very special relation that sometimes has been treated as a logical one, and I think that it was basically Kotarbiński's position. In consequence, the possible supplement of reistic reduction of examples of the above kind consists in the translation of relational verbs (like 'to destroy') to constructions with 'to cause' and descriptions of changing objects, and treating 'to cause' as a disguised logical relation.

The minor linguistic difficulty connected with the verb 'to destroy' is that not every case of causing the destruction of something is destroying it, like not every causing of human death is killing somebody - compare the popular slogan 'Guns don't kill people. People kill people', though changes in guns can obviously cause human deaths (changes in humans). As I will argue later, the relational verb 'to cause' can be literally substituted by other verbs only in case of actions performed by agents. An explosion of a volcano is not an action, at least for the people who do not believe in ancient myths. So we can say that the exploding Vesuvius killed many people, as well as destroying Pompeii and Herculaneum, only in the non-literal sense. In fact, it only caused many deaths and caused the destruction of Pompeii and Herculaneum (or better, caused Pompeii and Herculaneum to disintegrate). This problem indicates that there is something special about agency, at least on the linguistic level, and I will focus on this problem at the end of the paper.

A much more serious difficulty with the proposed solution is connected with the logical reduction of 'to cause'. As I suggested earlier, it is possible that Kotarbiński intended to reduce the causal relation to the logical one:

The event $B$ is the effect of the earlier change $A$, at a moment $t$, and the change $A$ is the cause of $B$ if and only if $A$ is an essential element of the sufficient condition of the event $B$ in respect of the moment $t$ and a causal regularity of the succession of events [Treatise: 27$]^{8}$

Kotarbiński intended to treat sentences about causal relation between particular changing objects" as instances of "causal regularities of the succession of events" or simply causal laws. Causal laws are of the form of general

obviously owes much to J. S. Mill, though he criticizes his views as sometimes unclear. The subsequent claims about Kotarbiński's notion of causality do not pretend to be a profound reconstruction of his views, but rather claims about some aspect of his views about causality that can be encountered in his papers.

${ }^{8}$ His fragment is a good example of normal event language.

${ }^{9}$ In fact he permanently used 'event language' as much more neat than consequent reistic language. 
equivalences. ${ }^{10}$ In consequence, the reistic reduction of the sentence 'Changing $A$ caused changing $B$ ' as an instance of a general law should be exactly as in Kotarbiński's formulation: ' $A$ changed in such way that $B$ changed (in the described way)'.

The main problem of the proposed reduction consists in an unclear logical form of the last sentence. The sentence as it stands has no clear truth conditions, because we do not know what is, in fact, the logical connective. In his article Causal Relations [1967] Davidson argued that there is no reduction (translation) of sentences about causal relation between individual events which are grammatically simple sentences, to the grammatically compound sentences with logical connectives, (see Davidson [1980], pp. 153-155).

Now we can come back to the general difficulty of Kotarbiński's contention that the sentences about changes in objects (events) can be reduced to sentences about changing objects. The difficulty in question is much more dangerous to Kotarbiński's position than the remarks presented above because it is possible that the demand of the reduction of the causal relation to the logical one is too excessive. Perhaps, as Kotarbiński argued in case of other relations, the changes in objects are causally related in many ways (e.g. destroying, killing, etc.) without using the ostensible name 'causal relation'. In consequence, Davidson's objection, which was just presented, is not dangerous for the very idea of reistic reduction. But here comes other Davidson's argument that undermines the very idea of reistic reduction of events. As Davidson argued in Adverbs of Action [1985] the logical form of sentences about events containing adverbs of action comprises existential quantification over events, which is not reducible in any plausible way. The idea is that the sentences in question have clear truth conditions if and only if they contain names of events and quantified events variables. In consequence, the names of actions cannot be treated as ostensible names.

The proposed correction of Kotarbiński's original formulation consists in treating the names of individual actions and events as real names, and, in consequence, individual actions and events as rightful individual things. This is the unique departure from Kotarbiński's original minimalist ontology that I propose in this paper. ${ }^{11}$ In particular, I do not want to reify the causal relation, and when I insist that a causal relation holds between individual events (conceived from now on as changes in individual things, and not as changing things) I only mean that the relevant sentence is true, e.g. "The explosion of Vesuvius caused the destruction of Pompeii and Herculaneum".

\footnotetext{
${ }^{10}$ Here I assume general form of causal law as in DAVIDSON [1967].

${ }^{11}$ The enriched ontology is not reistic. Events obviously cannot be counted as bodies.
} 
The aim of the rest of this paper is to show that the relation between some parts of an act or an action in Kotarbiński's sense can be established on the linguistic level. This nominalistic strategy is obviously not very remote from Kotarbiński's approach, but enables us to present his results in a simpler and more coherent form.

\section{Goals, means, reasons, motives and intentions}

Though Kotarbiński did not propose any strict definition of free impulse, which I treat here as a counterpart of the Davidsonian notion of action, it can be conceived as a goal-oriented change in an individual thing, or, as I assume here, a goal-oriented event.

According to Davidson, we redescribe in intensional terms or rationalize a performed action in terms of its goals when we give its reasons, i.e. proattitudes towards the actions of a certain type and a belief that the performed individual action is of this type (DAVIDSON [1980], pp. 3-4). The pro-attitude towards actions of a certain type can be considered the goal, and the belief that the performed action of a description given in the content of the belief belongs to this type usually expressing the means applied to perform the action in question. Of course, this distinction is rather vague because there is no clear borderline between goals and means. To illustrate it, let us consider Davidson's very well known example (see DAVIDSON [1980], pp. 57-58]. If the queen pours a poison into the king's ear, her action can be rationalized as follows: she wanted (or felt obliged, etc.) to kill the king (goal), and believed that pouring the poison into the king's ear is killing him (means to achieve the goal). Of course, there are other possible rationalizations: 'The queen wanted (or felt obliged) to kill the king and believed that poisoning him is killing him', or 'The queen wanted (or felt obliged) to poison the king and believed that pouring the poison into his ear is poisoning him'. The point is that goals and means to achieve the goals are not elements of ontology but elements of the language of description. This approach is not only compatible with Kotarbiński's reistic strategy, but it explains as well the lack of the strict borderline between goals and means as description dependent 'objects'.

The possible pro-attitudes towards a certain type of action can be various propositional attitudes, sometimes mutually exclusive - compare, e.g. 'I don't want to but I have to'. A definite pro-attitude together with a relevant belief constitute the reason of an action if they in fact cause this action. ${ }^{12}$ Many possible pro-attitudes can be counted also as motives to perform actions of

\footnotetext{
${ }^{12}$ We can be wrong about reason ascription of other people actions, as well as out own actions (self-deception).
} 
various type, but it is not necessary that a motive causes any action of the relevant type. The idea of the distinction between reason and motive was conceived in Paradoxes of Irrationality (DAVIDSON [1982]). The difference is very important, as somebody can have motives to act, but in fact he does not act, or even does not intend to act according to these motives.

The reason ascription is prone to error and self-deception, e.g. the queen can rationalize her action of poisoning the king stating that she felt obliged to stop the suffering of her ill husband. Sometimes we cannot give the reason of an action, but we know that there must be some reason, and this conviction suffices to treat the event as an action and not as something that just happened to somebodyt. If an action is performed, an agent can fail to achieve the goal by accident, or as a result of an error, e.g. the queen can cure the king's hearing instead of killing him. ${ }^{13}$

In this place, an additional remark is necessary. The description of reason as a cause in terms of attitudes (wants, beliefs, etc.) seems to have one disadvantage - the causes of events are just events, and reasons seem to be dispositions. Davidson insists that the description in terms of dispositions is just the result of our disability to individualize mental events that actualize these dispositions.

The other counterpart of the notion of goal is an intention. Of course, every performed action is by definition intentional because the pro-attitudes have intentional character (they are wants, obligations, etc), but what matters here is the action of forming an intention, which often does not result in a relevant action. The queen could have formed the intention to kill the king (a type of action), but she never even tried to perform any action of this type (poisoning, shooting or stabbing the king), or even, she deliberately helped to cure his illnesses, saved his life, etc. This is the problem of the weakness of will which constitutes an interesting problem in philosophy of action, especially in causal theories. ${ }^{14}$

\section{The problem of agency}

Every performed action is intentional, but the effects can be unintended. The intended or unintended effects were called by Kotarbiński works (dzieła):

The work is any effect of a cause that is a free impulse, and an effect is always an event (Treatise: p. 37).

\footnotetext{
${ }^{13}$ Of course the effects of the action strongly modify its description. If the king managed to survive the queen's action would be counted as an attempt to kill.

${ }^{14}$ This problem has been elaborated in DAVIDSON [1969].
} 
(...) the fact that an event is or is not a work of an agent in respect of his free impulse does not depend on his intention of realizing it (Treatise: p. 38).

The problem only touched on here by Kotarbiński can be labelled the problem of agency. Every action has an agent and we can speak about the works of the agent in respect of the action. But as an event, every action has its causal effects. The question is if the set of works of an agent in respect of the action is identical to the set of all effects of this action conceived as en event. At the first glance there are two extreme candidates for the solution. Work can be conceived as an immediate $^{15}$ effect of an action. But as immediate effects can have other effects, and these effects further effects, every effect in the causal chain initiated by the action can be considered work. Unfortunately, both solutions have obvious drawbacks. One can agree without hesitation that if the immediate effect ${ }^{16}$ of putting the poison into the king's ear is the illness of the king, and the further effect of the illness is his death, the king's death obviously counts as the queen's work. On the other hand, one of the effects of the death of the king can be a coup d'état initiated by one of the ministers, civil war, and even the division of the country. These events would hardly be counted as the queen's works, at least literally speaking. The problem is which effects of the causal chain initiated by an action cease to be the works of the agent or, in different terms, in what link of the causal chain initiated by the agents action the agency expires.

More generally, the problem of agency can be divided into two subproblems: the agent - action relation and the action - work relation. As I have just mentioned, Kotarbiński did not define the action (free impulse), but he gave some examples: pressing a button, striking a key, and agents' behavior, like:

(...) making an effort to recall a forgotten occurrence or straining attention when adding numbers (Treatise: p. 30).

This approach is analogous to Davidson's understanding of action, who insisted that all actions are in fact body-movements comprising conscious mental events like the ones mentioned by Kotarbiński. In consequence, planning an action or forming an intention to act are also actions (or free impulses). The notion of free impulse serves Kotarbiński to define the notion of an agent of an event:

An agent of an event is the one whose free impulse is a cause of the event (Treatise: $30)$.

\footnotetext{
15 'Immediate effect' means that there is no event in the causal chain between it and its cause. In Davidson's approach, actions can be conceived as immediate effects of their reasons.

${ }^{16}$ I treat the king's illness as an immediate effect of the queen's action only for the sake of an example. In fact, one can indicate a long causal chain between these events.
} 
This rather obvious definition is in fact not very illuminating because it does not explain the relation between an agent and a free impulse (an action). Moreover, it suggests that an agent conceived as a changing individual thing causes a free impulse ${ }^{17}$. This approach is known in the modern philosophy of action as agentcausation and is introduced usually to explain the freedom of the agent. Moreover, it is compatible with Kotarbiński's reism which does not admit events, and connects causation with changing objects. In the approach proposed in this paper, the relation between an agent and a free impulse (action) is a normal event causality - the cause of an action is its reason, i.e. a usually unknown mental event of an agent that can be described in terms of propositional attitudes. As Kotarbiński's reistic views evoke rather a suspicious notion of agent-causation, the Davidson's approach can be treated as another argument in favor of the contention that the cause of an action is not a changing agent but an event - the change in an agent.

Let us now focus on the problem of the relation between an action and a work. The work can be intentional or unintentional. Of course, the distinction between intentional and unintentional works is vague and ambiguous and strongly depends on the way we describe the events. If the queen committed an error and poured into the king's ear not a poison but a drug that cured his deafness, her work would be counted as unintentional. In this case, the action of the queen can be described as pouring a liquid into the king's ear, as pouring a drug into king's ear, or curing the king's deafness. As we can see, the descriptions of works of an agent can play an important role in describing the action. Of course, descriptions of works are not obligatory in describing actions which can be described in many different ways. An unsuccessful action can be described in terms of its causes, i.e. reasons: 'The queen wanted to kill the king and thought that pouring the liquid into his ear was killing him', or directly as an unsuccessful action: 'The queen tried to kill the king by pouring into his ear a liquid that she thought that was a poison'. Let us imagine that the queen managed to kill her husband because she wanted to remain queen after his death, marrying the king's younger brother, but she didn't know that one hour earlier that man had died. Her action could be described in terms of the mentioned effects of the action counted as the unintended works of the queen, e.g. as the extermination of the dynasty or becoming a lonely widow. Now let us imagine that the queen wanted to poison her husband because she wanted to stop being annoyed by his deafness. In this case, the accidental curing of the king's deafness can be described as stopping being annoyed, which turns to be an intended effect of the action, at least in this description.

\footnotetext{
${ }^{17}$ I do not maintain that this was Kotarbiński's position. I insist only that this view is compatible with some of his contentions.
} 
The examples given above serve only to prepare the answer to the question about the relation action - work. They indicate that any action can be described in potentially infinitely many ways. The problem of intended or unintended action is, in fact, the problem of its description in terms of intended or unintended effects (works), and it strongly depends on their description. In consequence, any action can be intentional and not-intentional depending on the way we describe it. The description of the effects appears to be the key to answering the question, which can be reformulated in the following terms: Which effects can used to describe an action? In his article Action and Responsibility [1965] Joel Feinberg introduced the notion of the accordion effect which applies exclusively to actions and not to non-action events. In his original approach, Feinberg understood action more or less as Kotarbiński defined it in Treatise, i.e. as a compound entity. The accordion effect permitted, if necessary, stretching the action over its reasons (causes) or effects. In Davidson's nominalist approach, the accordion effect does not consist in stretching an action, but in describing it (see DAVIDSON [1971]). If necessary, the same action can be described in terms of its reasons (as their effect), as a body movement (description as a physical event or as a free-impulse in Kotarbiński's approach), or in terms of its effects (as their cause). Moreover, every action description can differ from another depending on the circumstances we know and take into account. This is the reason I approximately identified actions with free impulses. In fact, free impulses, as Kotarbiński conceived them, are just actions under body-movement descriptions. Other elements of actions in Kotarbiński's sense are just counterparts of the possible elements of their descriptions.

The description of an action can be more or less precise, but the causal relation holds (or does not hold) between events independently of the way we describe them. According to Davidson, Feinberg's approach to the accordion effect obscures the very notion of action because it confuses the reality with its description. The causal relation holds between events independently of their description, but the choice of description depends on our knowledge and is usually pragmatically motivated. Some inconsistencies that can be traced in Treatise suggest that the same critical remark can be applied to Kotarbiński, who obscured his notion of action trying to introduce into it all elements of its possible descriptions. In consequence, the inexperienced reader of Treatise who does not know Kotarbiński's reism is prone to interpret an act as a compound and complicated entity embracing many elements with the rather obscure notion of causality. It can provoke confusions as in the following example:

Let us assume that John became the new javelin champion and beat the record of $n$ meters, while Peter, the non-living javelin ex-champion, could vaunt the throw 
of $m$ meters only. Did John cause with his throw that Peter's previous throw ceased the be the record? (Treatise: p. 34).

The example seems to be paradoxical because the effects cannot precede causes, and Kotarbiński proposes treating this example as a verbal speculation. From the presented point of view, the misunderstanding results from the fact that the description of a throw depends on changing circumstances and, in consequence, can change in time. The new throw is not the cause of changes in the previous one, but constitutes one of the circumstances that we take into account in its description. $^{18}$

From the Davidsonian point of view, the accordion effect enables the problem of the limits of agency to be established in the following way: instead of asking which effects of an action are the agent's works, and which are not, we can ask which effects can be used to describe the action. Let us consider once more the example of the queen poisoning her husband and assume that she was motivated to commit the crime by the king's brother. Motivating or manipulating the queen is obviously the action of the king's brother. But where does the agency of king's brother expire? i.e. which effects of his action can be used to describe his action? The action of the king's brother can be described as the utterance of words and gestures, as motivating (convincing or manipulating) the queen to kill her husband, as causing the queen to kill the king, or even as causing the king's death, but it cannot be called the killing of the king. Let us recall the Vesuvius example. In the case of agency, the verb 'to cause' can sometimes be eliminated in literal language, e.g. 'to cause destruction' can be literally substituted by 'to destroy' and 'to cause death' can be substituted by 'to kill'. Where the indicated substitution is possible, the effect of an action can be counted as the work of an agent.

The action of the king's brother can be called motivating (convincing or manipulating) to kill the king, because its possible effect can be the queen's reason to kill the king or the queen's reason to form the intention to kill the king. Killing the king or forming the intention to kill the king are, of course, the queen's actions, but the relevant reasons (i.e. reasons to kill the king or reasons to form the intention to kill the king) conceived as the queen's mental acts are, according to Davidson, not her actions ${ }^{19}$ and can be counted as the 'last' works of the king's brother in the causal chain of effects initiated by his action.

\footnotetext{
${ }^{18}$ Of course, the causal relation is present in this example, but it holds not between the two throws, but between the second throw and the action of renaming the first one.

${ }^{19}$ One of the most important conclusions in Davidson's Agency [1971] is that mental acts that are causes of our actions (the reasons) are in fact not actions. On the other hand forming intentions to act are actions.
} 
Now we can now draw the following conclusion: The agency expires when the effect of an action is another action. In consequence, the queen's action of pouring the poison into the king's ear can be called killing the king (if it was successful), trying to kill the king (if it was not successful), but it cannot be called (at least literally) the initiation of the civil war which was caused after the king's death. It can be called 'the provoking of the civil war', because the last and probably unintended work in the causal chain initiated by the queen's action was somebody's else reason to initiate the civil war.

\section{Concluding remarks}

The aim of this paper was to indicate that Kotarbińki's philosophy of action can be presented in a much simpler and more coherent form by adopting Davidson's nominalistic conceptual apparatus, with as few ontological concessions as possible. The presented approach to the notion of action does not depart in an essential way from the Kotarbiński's original theory, and the only ontological difference consists in introducing events as individual things. In consequence, the essential body of Kotarbiński's theory can be expressed in the proposed form.

As the concluding remark, let us focus on the problem of freedom. There is a strong reason to talk about human actions in special way, but from the ontological point of view they are just events that appear, as other events do, in causal chains. Analogously, in Kotarbiński's event-free original theory, actions are, in fact, changing individual conscious objects. In spite of the event-language of praxeological works, a free impulse is conceived not as a change in an agent, but as a changing agent which invokes ontologically suspected notion of agent causation introduced to explain the phenomenon of the freedom of an agent who initiates the changes in objects. In this paper I proposed that it is an agent's reason (and not the agent himself) that initiates chains of events. ${ }^{20}$ In order to preserve an agent's freedom, Davidson introduced the doctrine of anomalous monism, which assumes that all events (physical events, mental events, and actions) have the same ontological status and there is only one kind of causality. Contrary to Kotarbiński and many other philosophers, Davidson maintained that causal laws in form of generally quantified equivalences are 'language sensitive', i.e. can be formulated in physical language only. The freedom is preserved because action predicates are not physical predicates. In consequence, they cannot figure in causal laws and our actions are unpredictable or

${ }^{20}$ But, as Davidson maintains, the reasons of an action not actions. In consequence, planning, forming an intention to act, or volitions cannot be causes of actions. 
anomalous. I believe that this idea can be reconciled with Kotarbiński who explained the term 'free', as it occurs in 'free impulse', in the following way:

(...) by freedom we understand here the characteristics of deliberate behavior well known to the readers from their own experience, and not some indeterministic freedom of actions conceived as their independence on causes (Treatise: p. 32). ${ }^{21}$

\section{References}

DAVIDSON, D. [1963], “Actions, Reason, and Causes”, The Journal of Philosophy 60, 685-701. Reprinted in Davidson 1980: 3-9.

DAVIDSON, D. [1967], “Causal Relations”, The Journal of Philosophy 64, 691-713. Reprinted in Davidson 1980: 149-62.

DAVIDSON, D. [1969], "How is Weakness of the Will Possible?". Feiberg, J. (ed.) Moral Concepts. Oxford Readings in Philosophy, Oxford: Oxford University Press. Reprinted in Davidson 1980: 21-42.

DAVIDSON, D. [1971], “Agency”, [in:] Binkley, R., Bronaugh, R., Marras, A. (eds), Agent, Action, and Reason. University of Toronto Press. Reprinted in: Davidson 1980: 43-61.

DAVIDSON, D. [1980], Essays on Actions and Events. Oxford: Clerendon Press.

DAVIDSON, D. [1982], "Paradoxes of Irrationality", Wollheim, R., Hopkins, J. (eds) Philosophical Essays on Freud. Cambridge: Cambridge University Press: 289-305.

KOTARBIŃSKI, T. [1929], Elementy teorii poznania, logiki formalnej i metodologii nauk. Lwów: Second edition 1961.

KOTARBIŃSKI, T. [1955], Traktat o dobrej robocie. Wydział I Łódzkiego Towarzystwa Naukowego. Wydawnictwo Zakładu Narodowego im. Ossolińskich.

KOTARBIŃSKI, T. [1972], Abecadto praktyczności. Warszawa: Wiedza Powszechna.

${ }^{21}$ Kotarbiński's position expressed in this fragment, which bears some resemblance to Mills' views about freedom, is not very clear. 